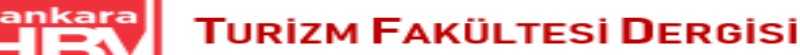

Dergi Ana Sayfası: https://dergipark.org.tr/tr/pub/ahbvtfd

ISSN: $2687-1912$

DOI: $10.34189 / \mathrm{tfd} .24 .02 .007$

\section{Profesyonel Aşçıların Tat ve Lezzet Kavramlarına İlişsin Bilgi Düzeylerinin Belirlenmesi}

(Determination of Knowledge Levels of Professional Chefs on Taste and Flavour Concepts)

\author{
*Dorukan BOYACI ${ }^{\mathrm{a}} \quad$ Melih İÇIGGEN ${ }^{\mathrm{b}}$ \\ a Kapadokya Üniversitesi, Kapadokya Meslek Yüksekokulu, Aşçılık Programı, Nevşehir-Türkiye (dorukan.boyaci@kapadokya.edu.tr) \\ https://orcid.org/0000-0002-0920-4777 \\ b Kapadokya Üniversitesi, Kapadokya Meslek Yüksekokulu, Aşçılık Programı, Nevşehir-Türkiye (melih.icigen@kapadokya.edu.tr) \\ https://orcid.org/0000-0002-4173-505x
}

\section{MAKALE GEÇMIŞ̧i}

\section{Gönderim Tarihi:}

03.08 .2021

\section{Kabul Tarihi:} 30.10 .2021

\section{Anahtar Kelimeler:}

Tat

Lezzet

Gastronomi

Şef/Aşçı $\ddot{0 ̈ Z}$

\begin{abstract}
Tat ve lezzet kavramlarının günlük dilde sık sık birbirlerinin yerine kullandıkları görülmektedir. Bu iki kavramın kullanım şekli ve doğru kullanılma durumunun belirlenmesi gıda ve turizm sektörü için oldukça önemlidir. Bu nedenle çalışmamızda profesyonel aşçların tat ve lezzet kavramlarına ilişkin bilgi düzeylerinin belirlenmesi amaçlanmıştır. Çalışma, Türkiye Aşçılar Federasyonu (TAFED)'e bağlı 396 profesyonel aş̧̧ı ile yapılmıştır. Araştırma verilerinin toplamasında anket formu kullanılmıştır. Bu çalışmanın sonuçlarına göre profesyonel aşçıların tat ve lezzet kavramlarına ilişkin net ve doğru bilgiye sahip olmadıkları belirlenmiştir. Bu nedenle tat ve lezzet arasındaki farklılığın ortaya koyulabilmesi için yeni araştırmalar yapılması ve kavramların tanımlarının net şekilde ortaya koyulması önerilmektedir.
\end{abstract}

\section{Keywords:}

Taste

Flavour

Gastronomy

Chef

Makalenin Türü: Araştırma Makales

\section{ABSTRACT}

It is seen that the concepts of taste and flavor are often used interchangeably in daily language. Determining the usage and correct usage of these two concepts is very important for the food and tourism sector. Therefore, in our study, it was aimed to determine the knowledge level of professional chefs about the concepts of taste and flavor. The study was conducted with 396 participants from the Turkish Chefs Federation (TAFED). Questionnaire form was used in data collection of the research. The last two questions of the survey questions consist of open-ended questions that describe the concepts. According to the results of this study, it has been determined that professional chefs do not have clear and accurate knowledge of the concepts of taste and flavor. For this reason, it is recommended to carry out new researches and to put forward the definitions of the concepts clearly in order to reveal the difference between taste and flavor.
\end{abstract}

*Sorumlu Yazar: Dorukan BOYACI

E posta: dorukan.boyaci@kapadokya.edu.tr

Makalenin Künyesi: Boyacı, D. ve İçigen, M. (2021). Profesyonel Aşçların Tat ve Lezzet Kavramlarına İlişkin Bilgi Düzeylerinin Belirlenmesi. AHBVÜ Turizm Fakültesi Dergisi, 24 (2), 310-329. 


\section{GIRIŞ}

Tat ve lezzet kavramlarına ilişkin farklı kurum ve kişiler tarafından yapılan farklı tanımlar bulunmaktadır. Türk Dil Kurumu, tat kelimesini "hoşa giden durum, lezzet”; lezzet kelimesini ise "ağız yoluyla alınan tat" olarak tanımlamaktadır (Türk Dil Kurumu, 2021). Dictionary of Food (2004), lezzeti, "yiyecek ve içeceklerin ağız içinde deneyimlenmiş tat ve koku duyumunun karışımı” olarak tanımlamaktadır. Bu sözlüğe göre, tat, dilden doğrudan ortaya çıkan bir sinir iletisi iken koklama duyusu, burnu, geniz boşluğunu ve serebral korteksin geniş bir alanını içermektedir. Uluslararası Standartlar Organizasyonu (ISO, 1992, 2008) ise lezzeti, "tadım sırasında algılanan koku alma, tat alma ve trigeminal duyumların karmaşık bileşeni" olarak tanımlamaktadır (Delwiche, 2004; Spence, 2012; Tournier, Sulmont-Rossé, \& Guichard, 2007). Spence ise tadı, dilde lokalize olan ve ağız boşluğunun herhangi bir yerinde meydana gelen tat alma reseptörlerinin doğrudan uyarılmasından kaynaklanan duyumlar olarak açıklamaktadır (Spence, Smith, \& Auvray, 2015).

"Tat" ve "lezzet" terimleri günlük dilin kullanımında birbirinin yerine kullanılan ve karıştırılan sözcükler olarak karşımıza çıkmaktadır. Kişiler bir yemeği beğendiğinde genellikle "tadının”, güzel olduğunu söylemektedir. Ne yazık ki lezzeti tanımlayan kelimeler nadiren tercih edilmektedir. Diğer bir ifadeyle, lezzet kavramı çoğunlukla imgelenerek açıklanmaktadır. Tüketicilerin lezzet ile ilgili görüşlerini çoğunlukla "iyi”, "güzel” ve "hoş" gibi yan kelimelere başvurarak ifade ettikleri belirtilmektedir (Boyacı, 2019). Bunun yanı sıra tat ve lezzet ayrımının zorluğu yalnızca günlük dilde değil, aynı zamanda bilimsel araştırmalarda da göze çarpmaktadır (Spence et al., 2015). Ayrıca, tat ve lezzet konulu çalışmaların bulunmasının yanı sıra bu iki kavramın farkının bilinmesi, ayırt edilmesi ve günlük hayatta kullanılması açısından herhangi bir çalışma bulunmamaktadır.

$\mathrm{Bu}$ çalışmada, Uluslararası Standartlar Organizasyonu'nun tanımı temel alınmıştır. Lezzet tanımlamasının ağız ve burnun birleşimi olarak düşünmek gerekliliğinden yola çıkılarak tat ve lezzet kavramları için farkındalık çalışması yapılması planlanmıştır. Tat ve lezzet kavramların önemi göz önüne alındığında özellikle gıda sektöründe çalışanların kavramları, kavramlar arası farkı bilmesi ve doğru kullanması oldukça önemlidir. $\mathrm{Bu}$ nedenle çalışmamızda profesyonel aşçıların tat ve lezzet kavramlarının ayrımına ilişkin bilgilerinin belirlenmesi amaçlanmaktadır. Türkiye Aş̧̧ılık Federasyonu (TAŞFED) 'na üye olan profesyonel aşçıların yemek yaparken veya yemeklerini anlatırken tat ve lezzet kavramlarını doğru bilip 
bilmedikleri ve profesyonel iş alanında bu kelimeleri doğru kullanıp kullanmadıkları görülmüş olacaktır. Bunun yanı sıra tat ve lezzet ayrımının tespit edilmesi ve günlük dilde ne oranda doğru kullanıldığı da gözlemlenecektir.

\section{KAVRAMSAL ÇERÇEVE}

\subsection{Kavram Yanılgısı}

Zihinsel bir yap1 veya onu temsilinden oluşan kavram, bir kişinin öğe veya öğenin gruplandırılması ile ilişkili olarak organize edilen bilgisinden oluşur. Bireyin zihinsel yapısı, belirli bir kavrama art arda daha yüksek anlayış seviyelerinde ulaştıkça değişir. Başlangıç düzeyinde, algılanabilir örneklere sahip bir kavramın zihinsel yapısı, o kavramın görsel görüntüsü gibi kolaylaştırıcılığa yardımcı olur. Bunun yanı sıra kavramlar, kelime veya kelimelerle ifade edilir. Kelimeler, aynı dili konuşanların birbirleriyle iletişim kurarken kullandıkları varlıklardır. Diğer ifadeyle, kelimeler kavramları adlandıran sembollerdir. Onlar, başlı başına kavramlar değildir (Klausmeier, 1992).

Kavramları ifade etmek onları tanımlamayı da gerektirir. Tanımlamaların genellikle farklı disiplinler arasında farklılık gösterdiği de bir gerçektir. Artan lezzet algısı araştırması alanında da tadı lezzetten tam olarak neyin ayırdığı sorusuna cevap vermek, aradaki farkı nasıl ayırt etmemiz gerektiğiyle ilgili tartışmalar için daha geniş çıkarımlara sahip olduğundan çok daha kritiktir (Spence et al., 2015). Stein vd. (2010: 1713), kavramları tanımlamanın önemini vurgulamak için fenomenler ile tanımlama arasındaki ilişkiyi şu ifade ile açıklamaktadır(Stein, Larrabee, \& Barman, 2008):

"Hangi fenomeni incelemeyi seçersek seçelim, her şeyden önce onu tanımlamalıyı. Bunu yapmak için anlambilim konusunu ele almalıyız çünkü farklı tanımlar farklı türde araştırma sorularına yol açar. Bunlar, sırayla, bu fenomenleri anlamamıza yardımcı olan kavramsal çerçeveleri nasıl inşa ettiğimizi belirler."

Bazı bilimsel kavramlar, bireylerin anlaması için zordur. Bu, çeşitli nedenlerle ortaya çıkabilir ancak birincil nedenlerden biri günlük deneyimlerin yanlış olduğunu destekleyen nitelikte olmasıdır (Stein et al., 2008). Kavram yanılgısı terimi, öğrencilerin veya bireylerin bilişsel yapısına bilimsel anlam dişında bir kere entegre edildikten sonra gerçek olan kavramın anlamını doğruluğunu ve öğrenmeyi engeller. Böylece yeni bilgiler onların bilişsel yapılarına uygun bir şekilde bağlanamaz ve kavram hakkında anlamada zayıflık veya yanlış anlamalar 
meydana getirir (Nakhleh, 1992). Kelimelerin günlük hayatta kullanıldığı anlamların, kavramın gerçek anlamı ile örtüşmemesi durumu da kavram yanılgısı olarak gösterilmektedir (Üce \& Ceyhan, 2019).

Klosse (2019), lezzet tanımında doğru kelimelerin eksik olduğunu söylemektedir. İnsanlar, yeni yedikleri ya da içtikleri yiyeceklerin lezzetini genelde kişisel olarak yorumlamaktadır. Diğer bir ifadeyle, Kişiler lezzetin terimsel bir tanımını vermek yerine kişisel yargılarını yansıtırlar. $\mathrm{Bu}$ düşünce kişilerin lezzeti betimlemesinin zayıflı̆̆ını, kelime hazinesinin eksikliğine ve tanımlama bilgisinin düşüklüğüne dayanmaktadır (Klosse, 2019).

\subsection{Tat ve Lezzet Kavramı}

Gıda, birçok farklı tat bileşenlerini ve tatları bulunduran karışık bir sistemdir. Gerçekte bazı temel tatlar (tatlı, ekşi, acı, tuzlu, umami) bulunmaktadır. Ancak bir yemek tadıldığında yüzlerce farklı tat algılanmaktadır. Bunun sebebi tatlar arasında meydana gelen bir dizi tat etkileşimi olduğu belirtilmektedir (Mason \& Nottingham, 2008). Tat alma duyusunu iki farklı kategoriye ayırabiliriz. Birincisi, insanda dilin kimyasal yapısını oluşturan yapıdır. Dilin yüzeyinde, tat papillalarının içinde yer alan birçok tat tomurcuğu vardır. Mantar şeklindeki (“mantar benzeri”) papillalar, bir veya daha fazla tat tomurcuğu içeren dilin ön kısmında yer alan pembemsi lekelerdir. Dilin arkasında, çevresel (“duvar benzeri”) papilla olarak adlandırılan 12 büyük tat tomurcuğu içeren papilla vardır. Tat tomurcukları ayrıca dilin arka taraflarında bulunan yapraklı ("yaprak benzeri”) papillalarda da bulunur. Bu yapı, temel tatlar olarak ifade edilen acı, ekşi, tatlı, tuzlu ve umamiyi oluşturur (Klosse, 2019; Lindemann, 1996; Schiffman, 2000). İkincisi, tat alma, lezzeti etkileyen bir araçtır. Tadım sırasında yanaklar, damak ve geniz (koku almayı sağlayan bölge) lezzeti destekleyen yan araçlar olduğu söylenebilir (Savarin, 2018). Örneğin, yanaklar ve damak, yutma işlemini kolaylaştırmak amacıyla tükürügü temin ettiği için lezzete katkı sağlayamaya yardımcı olur. Brillat-Savarin (2018), dili olmayan birinin tat alma duyusunda kayda değer bir değişiklik olmadığını söylemektedir. Bir insanın tat alma algısını gıdanın dilde kalma süresi ve gıdanın konsantrasyonu etkilemektedir. $\mathrm{Bu}$ nedenle baharatlar gibi keskin tatlar genelde çok beğenilmemektedir. Bununla birlikte gıda sıcaklığının tat algısını artırdığg tespit edilmiştir çünkü yüksek sıcaklıkta uçucu maddeler, kolaylıkla buharlaşarak koku almayı uyarır (Karakuş, 2013). 
Erişkinlerin tat tomurcuğu miktarı 3.000 ile 10.000 arasında değişmektedir (Kurtuldu, Miloğlu, Derindağ, \& Özdoğan, 2018). Ayrıca bazı hastalıklarda (beslenme bozukluğu, enfeksiyon ve bazı kanser türleri gibi) ve bu hastalıkların tedavileri nedeniyle kişilerin tat tomurcuklarında hasar meydana gelebilmektedir (Sonis, Faizo, \& Fang, 2004). Ayrica, insanlardaki hormonal durumlar da tat duyarlılı̆̆ını etkileyebilmektedir. Örneğin, bir çalışmada serotoninin tat alma eşiğini, yani acı ve ekşi tat eşiğini önemli ölçüde düşürdüğü bildirilmiştir (Heath, Melichar, Nutt, \& Donaldson, 2006). Kültürel farklılıklar da tadın algılanmasında etkili bir rol oynamaktadır. Yapılan bir çalışmada Amerikan halkının Japon halkına göre sakkaroz ve monosodyum glutamat tadını daha az ayırt ettiği belirtilmiştir (Ishii, Yamaguchi, \& O'Mahony, 1992; Karakuş, 2013).

Dictionary of Food (2004)'a göre lezzet; “yiyecek ve içeceklerin ağız içinde deneyimlenmiş tat ve koku duyumunun karışımı"dır. Bu sözlüğe göre tat, dilden doğrudan meydana gelen bir sinir iletisi iken, koklama duyusu, burnu ve serebral korteksin geniş bir alanını içerir ve bir dereceye kadar kültürel olarak belirlenir. Webster's Third New International Dictionary (1993)'e göre lezzet ise; “tat alma duyusunu etkileyen ya da damağı sevindiren bir şeyin kalitesi” dir. Lezzet algısı birçok disiplin tarafından incelenmiştir. Lezzet algısı çalışmalarında psikolojik (Prescott, 2015), somato-sensori (Piqueras-Fiszman \& Spence, 2012), nörogastronomi (Shepherd \& Shepherd, 2011) ve duyusal (Spence et al., 2015)incelemeler yapılmıştır.

Lezzet algısı günlük deneyimlerimizin çoklu duyusal algılarımızdan biridir. Tat, yiyecek ve içeceklerin kokusu (aroma) gibi merkezi bir rol oynar. Örneğin baharatlı yiyeceklerle ilişkili yanma hissi ile ilgili ağız hissi, doku, sıcaklık ve trigeminal ipuçlarıyla ilgili dokunsal ipuçlarını sağlamaktadır. Bunun da ötesinde, başta gıda rengiyle ilgili olanlar olmak üzere görsel ipuçları, bazen bir gıdanın lezzetinin algılanan kimliği ve yoğunluğu üzerinde de güçlü bir etki gösterir (Spence et al., 2015). Son olarak, yemek yerken çıkardığımız seslerin de patates cipsi, kraker ve kahvaltılık gevrek gibi yiyeceklerin gevreklik ve çıtırlık lezzet algımızı etkilediği gösterilmiştir. Lezzet tanımlarında bireyler, meyveli, etli, baharatlı, küflü, bayat, kremsi gibi tanımlayıcılar kullanmaktadır. Bununla beraber, trigeminal duyumlar, "baharatlı", "keskin", “acı" ve "gazlı" gibi gıda tanımlayıcılarının lezzet algısına kolayca dahil edilebilir (Spence et al., 2015). Lezzet kavramı, birçok deneyim gibi çoklu algısal bir 
süreçtir ve sadece tat alma duyusu ile açıklanamaz. Kısacası, tat alma duyusuna kokular ve trigeminal duyumlar eşlik etmektedir.

Lezzet ve tat algısını etkileyen etmenler duyusal analiz ile ortaya koyulabilmektedir. Kişiye göre lezzet algısının farklı olduğu ve bu farklılıkların oluşmasında gıda komponentlerinin yanında yaş, cinsiyet, mevsim, sigara, renkler, hastalıklar, ilaç kullanımı gibi birçok faktörün de etkili olduğu belirtilmektedir. (Karaman \& Çetinkaya, 2020). Ayrıca lezzet oluşumunda tat alma duyusunu tek başına yeterli olduğunu düşünmek doğru değildir. Tat alma duyusu ile birlikle diğer duyularımız (koku, görme, işitme ve dokunma duyuları) da lezzeti etkilemektedir. Koku alma duyusu (mis, bayat, hoş, nahoş vb.) birçok gıdanın lezzet tanımını değiştirebilmektedir. Örneğin bir yiyecekten alınan bayat kokusu tüketiciye lezzetsiz ve bozulmuş olarak gelebilmektedir. Kokunun yanında, dokunma duyusu (tazelik, sıcak-soğuk, yağl1-yağsı), görsel özellikler (markası, ambalaj1, estetik görünümü, rengi, yoğunluğu, buharı vb.) ve işitme duyusu da (çıtır, tazelik, gevreklik, hüpletme, lıkır lıkır vb.) tat almada etkilidir. (Elder \& Krishna, 2010; Krishna, 2012).

Koklama duyusu, diğer duyulara göre daha karmaşıktır. Koklama, aroma ve uçucu kokular tarafından çok fazla çeşitlidir. Bunun yanı sıra, tat alma duyusuna göre koklama, deneyim ve kültür açısından incelendiğinde daha fazla karmaşıklık içerir. Örneğin, Türkiye'de yaşayan bir birey için limon kokusunu almak ne kadar kolay görünse de limonu tatmamış ve koklamamış birey için aynı yargıyı söylemek pek kolay olmayabilir (Lawless, 1991). Koku alma duyusunun iki bölgesi bulunmaktadır: Orthonasal ve Retronasal bölge. Orthonasal bölge, doğrudan burunla ilgilidir. Nesnelerin olumlu veya olumsuz kararları burundan koku alarak verilir. Retronasal bölge ise, iç burun olarak adlandırılır. Beyin, tabii ki bireyler aromaları tanımlamak için bu algı bölgesine başvurur (Spence, Levitan, Shankar, \& Zampini, 2010). Dolayısıyla, koku algısı, burun ve geniz boşluğu olmak üzere iki açıdan ilgi çekicidir. Araştırmacı koku duyusunun ağızla mı yoksa dış etkenlerle mi yönlendirildiğine bağlı olarak niteliksel olarak iki farklı şekilde algılanacağını öne sürmektedir.

Brillat-Savarin (2018), koku ve tat duyusu arasındaki bağlantıyı etkileyici ifadelerle ve ispatlarla anlatmıştır. Araştırmacı, burnu, "kim var orada?" diye haykıran ileri karargâh nöbetçisine benzetmektedir. Ayrıca, ağzın laboratuvar, burnun baca olduğunu ve bu ikisinin tek bir duyu oluşturduğunu metaforlarla açıklamıştır. Bunun yanı sıra, koku duyusunun 
önemini vurgulamak için üç deneyden bahsetmiştir. Birincisi, kişi nezle olursa lezzet alamayacağına dair bilimsel bir görüştür. İkincisi, burun tıkanarak yemek yemeğe çalış1lırsa orthonasal bölge kapanacağı için koku alınamayacağını, dolayısıyla lezzetin farkına varılamayacağını söylemektedir. Brillat-Savarin, burun tıkama işlemi yaparak mide bulandırıcı ilaçların rahatlıkla içilebileceğini iddia etmektedir. Üçüncü deney ise, gıdanın yutulma sırasında dil damağa yapıştırılırsa hava akımının engelleneceğinden dolayı koku alma işlemin gerçekleşmeyeceğini söylemektedir. Savarin (2018), koku almanın engellenmesinden iki sonuç çıkarmaktadır. Birincisi, koku alma duyusu olmadan aromalar alınamadığı için lezzet algısı da gelişemez. İkincisi, koku alma duyusu iki modaliteyi içerdiğinden birinin kapatılması (hangisi olduğu fark etmez) koklama duyusunu doğrudan olumsuz etkileyecektir.

Bazı kokular, kişiler tarafından tat duyusuna benzetilerek "şekerimsi" veya "tatlı" olarak algılanmaktadır. Bunun iki nedeni bulunmaktadır. Birincisi, tadılan bir gidanın lezzet özelliğinin aslında koklanarak uygulandığına dair bilginin bireyler tarafından bilinmediğidir. Kısacası, tatlılık aslında belirli kokuların sanki bir parçası görünmektedir. İkincisi, tatlılığın kokusunun tadına bakılarak anlaşılan bir tat olduğu söylenmesidir. Örneğin, çileğin tatlı tadının doğrudan nasıl koktuğunu (ortonasal olarak) düşünürüz. Aslında, tatlılığın kokladığımız gıda ile olan ilişkisi, kişilerin önceki defalarca olan deneyimin retronasal olarak tespit edilen o gıdanın kokusundan ayrılmazlığı ile belirlenir (Spence et al., 2015). Diğer bir ifade ile söylenirse, çilek, vanilya ve karamel gibi gıdalar tatlı tat olarak ifade edilmektedir. Aslında bu gıdalar hiçbir tat özelliğini içermemesine rağmen retronasal deneyimden dolayı tat alma duyusu ile ilişkilendirilir. Diğer açıdan bakıldığında, bu gıdaları tatmamış ve koklamamış toplumlar ve kişiler, gıdaların muhtemelen tatlılıkla daha az eşleşmesi nedeniyle bu kokuların bir kısmını tatlı olarak tarif edemeyebilirler (Auvray \& Spence, 2008).

Trigeminal sinir, ön ağız boşluğu ve dili, burun boşluğu, yüz ve kafa derisinin kısımlarını içeren geniş bir innervasyon alanına sahiptir. $\mathrm{Bu}$ sinir, burundaki kimyasal tahrişin özel aracısı olduğundan ve ağzın geniş bir alanına hizmet ettiğinden, kemosensöri çalışmaları yapan bilim insanları genellikle kimyasal duyarlılı̆̆ı "trigeminal duyarlılık" olarak adlandırmışlardır. Ağız boşluğundaki tat sinirlerinden anatomik olarak ayrılmalarına paralel olarak, burundaki trigeminal reseptörler farklıdır ve koku alma reseptörlerinden ayrılmaktadır (Spence et al., 2015). Bununla birlikte, trigeminal sistemin genellikle lezzet algısına katkıda 
bulunduğu artık yaygın olarak kabul edilmektedir (Han et al., 2021; Viana, 2011). Trigeminal sistemin aktivasyonu, örneğin acı biber veya hardal yediğimizde meydana gelir. Ağızda bir 1sı hissi ve bazen de burun köprüsünde sıkışma, ağrılı bir his uyandıran şey budur (Lawless, Rozin, \& Shenker, 1985). Ayrıca bazı keskin aromalı/kokulu denilebilecek yiyeceklere de katkı sağlar. Örneğin, nane aromalı bir gıda tüketirken serin his trigeminal algıdan dolayıdır (Nagata, Dalton, Doolittle, \& Breslin, 2005). Tat, koku, dokunma, işitme, görme duyuları ve trigeminal sistem arasındaki etkileşimlerin çokluğu, çok sayıda araştırmacının (Abdi, 2002; Boyacı, 2019) yeme eylemiyle birleşen bu sistemlerin kombinasyonları için bir terim olarak lezzeti önermesine yol açmıştır. Lezzet algısı, duyuların, kişilerin psikolojik boyutların, kişisel deneyimin ve kimyasal hislerin olumlu veya olumsuz etkileri ile ortaya çıkmaktadır (Boyac1, 2019; Prescott, 2015; Spence et al., 2010).

\section{YÖNTEM}

Bu çalışma Türkiye' de profesyonel mutfaklarda çalışan aşçıların lezzet ve tat ayrımının bilinirliğini gözler önüne sermek amacıyla tanımlayıcı düzeyde tasarlanmıştır. Böylelikle gıda sektörünün profesyonelleri olan aşçı/şeflerin tat ve lezzeti bilip bilmedikleri incelenecektir. $\mathrm{Bu}$ araştırmanın evreni Türkiye Așçılar ve Şefler Federasyonu (TAŞFED) bünyesinde bulunan 20 derneğin 18.000 profesyonel aşçı üyelerinden oluşturmuştur. $\mathrm{Bu}$ araştırmada amaçlı örnekleme yöntemi kullanılmıştır. Sencer’e (1989) göre amaçlı örnekleme, evrenin sorununa en uygun bir kesimini gözlem konusu yapmak demektir. Belirlenmiş bir tabakadan, araştırmanın amacı doğrultusunda yeni örneklem seçimi amaçlı örneklemedir (Johnson \& Christensen, 2008). Amaçlı örneklemde her bir tabaka homojen bir örnek oluşturmaktadır. Genellikle birden çok ve farklı özelliklerdeki evrenlere (örneğin ordu mensupları, öğretmenler, bankacılar ve opera sanatçıları gibi farklı meslek grupları) erişilmek istenilen durumlarda kullanılmaktadır (McNabb, 2015). Araştırmanın örneklemi \%95 güven aralığında 377 olarak hesaplanmıştır. Araştırmaya katılmayı kabul eden ve belirlenen çalışma süresinde anketleri cevaplayan 396 katılımcıdan veriler toplanmıştır. Araştırma Mart 2021 ile Haziran 2021 tarihleri arasında yapılmıştır.

$\mathrm{Bu}$ çalışma kapsamında anket formu literatür doğrultusunda araştırmacılar tarafından oluşturulmuş olup üç bölümden meydana gelmektedir. Birinci bölüm, demografik özellikleri içeren Kişisel Bilgi Formu 6 sorudan oluşmaktadır. İkinci bölüm, "Tat" ve "Lezzet" farkındalığına yönelik "Evet"- "Hayır"- "Fikrim yok" seçenekleri bulunan 12 adet soruyu 
içermektedir. Üçüncü bölümde ise, lezzet ve tat kavramlarının farklılıklarını ortaya koyabilmek adına 2 adet açık uçlu soru sorularak katılımcılardan bu açık uçlu sorulara tek kelime ile cevap vermeleri istenmiştir. Araştırmacılar tarafından hazırlanan anket formu için alanında uzman ve araştırmaya dahil olmayan 3 araştırmacıdan uzman görüşü alınmıştır. Anket online ortamda Google form aracılığıyla oluşturulmuş ve katılımcılara Türkiye Aşçılar ve Şefler Federasyonu (TAŞFED) yardımıyla üyelerine mail yolu ile iletilmiştir.

Anket sonucu elde edilen veriler SPSS programı ile analiz edilmiştir. Araştırma verilerin analizinde sayı, yüzdelik hesaplaması, frekanslarının dağılımı ve Ki kare (Chi Square) Bağımsızlık testi kullanılmıştır.

Katılımcıların anketin açık uçlu son 2 sorusuna kelimelerle verdikleri cevaplar ile profesyonel aşçıların tat ve lezzet farklılıklarını gösterebilmek adına tablolaştırılmıştır.

Lezzet ve tat kavramlarının ayrımının bilinirliğini belirlemek için yapılan bu araştırmanın hipotezleri aşağıdaki gibi kurulmuştur.

H1: Profesyonel Mutfaklarda Çalışan Aşçılar Lezzet ve Tat Arasındaki ayrımı bilmektedir.

\subsection{Etik Hususlar}

Araştırma yapılmadan önce Kapadokya Üniversitesi Bilimsel Araştırma ve Yayın Etiği kurulundan "Etik Kurul” izni alınmıştır. (Karar no: 2021.51) Katılımcılara çalışmanın amacı ile ilgili açıklama yapılarak kişisel verilerinin gizli tutulacağı hakkında bilgi verilmiştir.

\section{BULGULAR}

Çalışmada ilk olarak demografik özelliklerin dağılımı verilmiştir.

Tablo 1. Katılımcıların sosyo-demografik özelliklerinin dağılımı

\begin{tabular}{|c|c|c|c|}
\hline \multicolumn{2}{|l|}{ Değişkenler } & $\mathbf{n}$ & $\%$ \\
\hline \multirow{2}{*}{ Cinsiyet } & Erkek & 310 & 78,3 \\
\hline & Kadın & 86 & 21,7 \\
\hline \multirow{3}{*}{$\begin{array}{l}\text { Yaş } \\
\left(\bar{X}_{ \pm S S S}, 33,44 \pm 9.41\right)\end{array}$} & $18-28$ & 136 & 34,3 \\
\hline & $29-39$ & 160 & 40,4 \\
\hline & 40 Yaş ve Üzeri & 100 & 25,3 \\
\hline \multirow{5}{*}{ Eğitim Durumu } & İlkögrretim & 64 & 16,2 \\
\hline & Lise & 144 & 36,4 \\
\hline & Önlisans & 96 & 24,2 \\
\hline & Lisans & 78 & 19,7 \\
\hline & Lisansüstü & 14 & 3,5 \\
\hline \multirow{2}{*}{$\begin{array}{ll}\text { Mutfakta } & \text { Mevcut } \\
\text { Pozisyon } & \\
\end{array}$} & Aşçıbaşı & 94 & 23,7 \\
\hline & Aşçıbaşı Yardımcısı & 60 & 15,2 \\
\hline
\end{tabular}




\begin{tabular}{|c|c|c|c|}
\hline & Kisım Şefi & 76 & 19,2 \\
\hline & Kısım Şefi Yardımcısı & 48 & 12,1 \\
\hline & $A s ̧ c ̧ \iota$ & 118 & 29,8 \\
\hline \multirow{4}{*}{$\begin{array}{l}\text { Mutfakta } \\
\text { Deneyim Süresi }\end{array}$} & $1-3 Y l l$ & 52 & 13,1 \\
\hline & $4-6 Y_{l} l$ & 72 & 18,2 \\
\hline & $7-9 Y_{l l}$ & 48 & 12,1 \\
\hline & 10 Yll ve Üzeri & 224 & 56,6 \\
\hline Toplam & & 396 & 100 \\
\hline
\end{tabular}

Katılımcıların \%78,3'ü erkek $(n=310), \% 40,4$ 'ü $(n=160) 29$ ile 39 yaş aralığında, \%36,4'ü $(\mathrm{n}=144)$ lise mezunu ve katılımcıları yaş ortalaması 33,44 $\pm 9,41$ 'dir. Araştırmaya katılanların \%29,8'inin ( $\mathrm{n}=118)$ aşçı pozisyonunda çalıştı̆̆ $1, \% 56,6$ 'sının $(\mathrm{n}=224) 10$ yıl ve üzeri tecrübeye sahip oldukları görülmektedir (Tablo 1).

Tablo 2. Soruların frekanslarının dağılımı

\begin{tabular}{|c|c|c|c|c|c|c|}
\hline \multirow{2}{*}{ Sorular } & \multicolumn{2}{|c|}{ Evet } & \multicolumn{2}{|c|}{ Hayır } & \multicolumn{2}{|c|}{ Fikrim yok } \\
\hline & $\mathbf{n}$ & $\%$ & $\mathbf{n}$ & $\%$ & $\mathbf{n}$ & $\%$ \\
\hline $\begin{array}{l}\text { Bir gida ürününün tadına } \\
\text { bakmadan } \\
\text { bilebilirim. }\end{array}$ & 156 & 39,4 & 228 & 57,6 & 12 & 3,0 \\
\hline $\begin{array}{l}\text { Lezzet algimı dokunma } \\
\text { duyusu etkiler. }\end{array}$ & 222 & 56,1 & 158 & 39,9 & 16 & 4,0 \\
\hline $\begin{array}{l}\text { Tat algımı koklama duyusu } \\
\text { etkiler. }\end{array}$ & 356 & 89,9 & 36 & 9,1 & 4 & 1,0 \\
\hline $\begin{array}{l}\text { Bir gida ürününü yemeden } \\
\text { tadını bilebilirim. }\end{array}$ & 132 & 33,3 & 246 & 62,1 & 18 & 4,5 \\
\hline $\begin{array}{l}\text { Lezzet ve Tat arasındaki } \\
\text { fark1 biliyorum. }\end{array}$ & 380 & 96,0 & 10 & 2,5 & 6 & 1,5 \\
\hline 5 farklı ana tat alg1s1 vardır. & 272 & 68,7 & 54 & 13,6 & 70 & 17,7 \\
\hline $\begin{array}{l}\text { Tat alma, insanın beş temel } \\
\text { duyusundan biridir. }\end{array}$ & 364 & 91,9 & 18 & 4,5 & 14 & 3,5 \\
\hline $\begin{array}{l}\text { Tat alma öğrenilen bir } \\
\text { duyudur. }\end{array}$ & 266 & 67,2 & 118 & 29,8 & 12 & 3,0 \\
\hline $\begin{array}{l}\text { Lezzet algisı tat alma } \\
\text { duyusuyla ilişkilidir. }\end{array}$ & 386 & 97,5 & 4 & 1,0 & 6 & 1,5 \\
\hline $\begin{array}{lll}\text { Lezzet algis1 } & \text { koku } \\
\text { duyusuyla ilişkilidir. } & \end{array}$ & 340 & 85,9 & 42 & 10,6 & 14 & 3,5 \\
\hline $\begin{array}{l}\text { Bir yemeğin tadını diğer } \\
\text { duyular etkileyebilir. }\end{array}$ & 284 & 71,7 & 92 & 23,2 & 20 & 5,1 \\
\hline $\begin{array}{l}\text { Bir yemeğin lezzetini diğer } \\
\text { duyular etkileyebilir. }\end{array}$ & 300 & 75,8 & 82 & 20,7 & 14 & 3,5 \\
\hline
\end{tabular}

"Lezzet algisı tat alma duyusuyla ilişkilidir." ifadesine katılımcıların \%97,5'i ( $\mathrm{n}=386)$, “Lezzet ve Tat arasindaki farkı biliyorum." ifadesine ise \%96,0's1 (n=380), “Tat 
alma, insanın beş temel duyusundan biridir." ifadesine \%91,9'u (364) evet cevab1 vermişlerdir (Tablo 2).

Tablo 3. Profesyonel mutfaklardaki toplam deneyim süresi ile 5 farklı ana tat algısının bilinirliği arasındaki ilişkiye yönelik ki kare analizi

\begin{tabular}{|c|c|c|c|c|c|c|c|c|}
\hline \multirow{3}{*}{$\begin{array}{l}\text { Mutfakta } \\
\text { Toplam } \\
\text { Deneyim } \\
\text { Süresi }\end{array}$} & \multicolumn{8}{|c|}{5 Farklı Ana Tat Algısı Vardır. } \\
\hline & \multicolumn{2}{|c|}{ Evet } & \multicolumn{2}{|c|}{ Hayır } & \multicolumn{2}{|c|}{ Fikrim yok } & \multicolumn{2}{|c|}{ Toplam } \\
\hline & $\mathbf{n}$ & $\%$ & $\mathbf{N}$ & $\%$ & $\mathbf{n}$ & $\%$ & $\mathbf{n}$ & $\%$ \\
\hline $1-3$ Yll & 38 & 14,0 & 4 & 7,4 & 10 & 14,3 & 52 & 13,1 \\
\hline $4-6$ Yll & 50 & 18,4 & 18 & 33,3 & 4 & 5,7 & 72 & 18,2 \\
\hline $7-9$ Yll & 36 & 13,2 & 4 & 7,4 & 8 & 11,4 & 48 & 12,1 \\
\hline 10 Yıl ve Üzeri & 148 & 54,4 & 28 & 51,9 & 48 & 68,6 & 224 & 56,6 \\
\hline Toplam & 272 & 100,0 & 54 & 100,0 & 70 & 100,0 & 396 & 100,0 \\
\hline Test Değeri & \multicolumn{8}{|c|}{$17.888^{* * *}$} \\
\hline $\mathbf{p}$ & \multicolumn{8}{|c|}{$0.007 *$} \\
\hline
\end{tabular}

$* \mathrm{p}<0.05, * *$ Pearson Ki Kare Testi

Profesyonel mutfaklardaki toplam deneyim süresi ile 5 farklı ana tat algısının bilinirliği arasındaki ilişkiyi test etmek için ki kare analizi uygulanmıştır. Bunun sonucunda, mutfaktaki toplam deneyim süresi ile 5 farklı ana tat algısının bilinirliği arasında istatistiksel olarak anlamlı bir ilişki olduğu görülmektedir $\left(X^{2}=17.888, \mathrm{p}<0.05\right) .5$ farklı ana tat algısının bilinirliği ifadesine evet cevabını veren katılımcıların \%54,4'ünün (n=148), hayır cevabını veren katılımcıların \%51,9'unun $(\mathrm{n}=28)$ ve fikrim yok cevabını veren katılımciların \%68,6'sının (n=48) mutfaktaki toplam deneyim süresinin 10 yıl ve üzeri olduğu görülmektedir (Tablo 3). Katılımcıların mutfaklarda deneyim süresi arttıkça tat algısı bilinirliği de arttığı görülmektedir.

Tablo 4. Profesyonel mutfaklardaki toplam deneyim süresi ile lezzet ve tat arasındaki fark1 biliyorum cevabı arasındaki ilişkiye yönelik ki kare analizi

\begin{tabular}{|c|c|c|c|c|c|c|c|c|}
\hline \multirow{3}{*}{$\begin{array}{l}\text { Mutfakta } \\
\text { Toplam } \\
\text { Deneyim } \\
\text { Süresi }\end{array}$} & \multicolumn{8}{|c|}{ Lezzet ve Tat arasındaki farkı biliyorum. } \\
\hline & \multicolumn{2}{|c|}{ Evet } & \multicolumn{2}{|c|}{ Hayır } & \multicolumn{2}{|c|}{ Fikrim yok } & \multicolumn{2}{|c|}{ Toplam } \\
\hline & $\mathbf{n}$ & $\%$ & $\mathbf{n}$ & $\%$ & $\mathbf{n}$ & $\%$ & $\mathbf{n}$ & $\%$ \\
\hline $1-3$ Yıl & 44 & 11,6 & 4 & 40,0 & 4 & 66,7 & 52 & 13,1 \\
\hline $4-6$ Yıl & 70 & 18,4 & 0 & 0,0 & 2 & 33,3 & 72 & 18,2 \\
\hline $7-9$ Yil & 42 & 11,1 & 6 & 60,0 & 0 & 0,0 & 48 & 12,1 \\
\hline 10 Yıl ve Üzeri & 224 & 58,9 & 0 & 0,0 & 0 & 0,0 & 224 & 56,6 \\
\hline Toplam & 380 & 100,0 & 10 & 100,0 & 6 & 100,0 & 396 & 100,0 \\
\hline Test Değeri & \multicolumn{8}{|c|}{$39.354 * *$} \\
\hline $\mathbf{p}$ & \multicolumn{8}{|c|}{$0.000 *$} \\
\hline
\end{tabular}


Profesyonel mutfaklardaki toplam deneyim süresi ile lezzet ve tat arasındaki farkın bilinirliği arasındaki ilişkiyi test etmek için ki kare analizi uygulanmıştır. Bunun sonucunda, mutfaktaki toplam deneyim süresi ile lezzet ve tat arasındaki farkın bilinirliği arasında istatistiksel olarak anlamlı bir ilişki olduğu görülmektedir $\left(X^{2}=39.354, \mathrm{p}<0.05\right)$. Lezzet ve tat arasındaki farkın bilinirliği ifadesine evet cevabını veren katılımcıların \%58,9'unun (n=224), mutfaktaki toplam deneyim süresinin 10 yıl ve üzeri olduğu görülmektedir (Tablo 4). Katılımcıların deneyim süresi arttıkça tat ve lezzet arasında farkın bilindiği görülmektedir.

Tablo 5. Profesyonel mutfaklardaki toplam deneyim süresi ile tat alma, insanın beş temel duyusundan biridir sorusu arasındaki ilişkiye yönelik ki kare analizi

\begin{tabular}{|c|c|c|c|c|c|c|c|c|}
\hline \multirow{3}{*}{$\begin{array}{l}\text { Mutfakta } \\
\text { Toplam } \\
\text { Deneyim } \\
\text { Süresi }\end{array}$} & \multicolumn{8}{|c|}{ Tat alma, insanın beș temel duyusundan biridir. } \\
\hline & \multicolumn{2}{|c|}{ Evet } & \multicolumn{2}{|c|}{ Hayır } & \multicolumn{2}{|c|}{ Fikrim yok } & \multicolumn{2}{|c|}{ Toplam } \\
\hline & $\mathbf{n}$ & $\%$ & $\mathbf{n}$ & $\%$ & $\mathbf{n}$ & $\%$ & $\mathbf{n}$ & $\%$ \\
\hline $1-3$ Yıl & 50 & 13,7 & 0 & 0,0 & 2 & 14,3 & 52 & 13,1 \\
\hline $4-6$ Yll & 72 & 19,8 & 0 & 0,0 & 0 & 0,0 & 72 & 18,2 \\
\hline $7-9$ Yll & 46 & 12,6 & 2 & 11,1 & 0 & 0,0 & 48 & 12,1 \\
\hline 10 Yll ve Üzeri & 196 & 53,8 & 16 & 88,9 & 12 & 85,7 & 224 & 56,6 \\
\hline Toplam & 364 & 100,0 & 18 & 100,0 & 14 & 100,0 & 396 & 100,0 \\
\hline Test Değeri & \multicolumn{8}{|c|}{$15.882 * *$} \\
\hline p & \multicolumn{8}{|c|}{$0.006^{*}$} \\
\hline
\end{tabular}

$* \mathrm{p}<0.05, * *$ Fisher's Exact Testi

Profesyonel mutfaklardaki toplam deneyim süresi ile "tat alma, insanın beş temel duyusundan biridir" ifadesi arasındaki ilişkiyi test etmek için ki kare analizi uygulanmıştır. Bunun sonucunda, mutfaktaki toplam deneyim süresi ile tat alma, insanın beş temel duyusundan biridir ifadesi arasında istatistiksel olarak anlamlı bir ilişki olduğu görülmektedir $\left(X^{2}=15.882\right.$, $\mathrm{p}<0.05$ ). Tat alma, insanın beş temel duyusundan biridir ifadesine evet cevabını veren katılımcıların \%53,8'inin ( $\mathrm{n}=196)$, hayır cevabını veren katılımcıların \%88,9'unun ve fikrim yok cevabını veren katılımcıların \%85,7'si $(n=12)$ mutfaktaki toplam deneyim süresinin 10 yıl ve üzeri olduğu görülmektedir (Tablo 5). Mesleki deneyimle birlikte tat alma duyusunun beş temel duyudan biri olduğunun bilinirliği artmaktadır. 
Tablo 6. Profesyonel mutfaklardaki toplam deneyim süresi ile tat alma öğrenilen bir duyudur sorusu arasındaki ilişkiye yönelik ki kare analizi

\begin{tabular}{|c|c|c|c|c|c|c|c|c|}
\hline \multirow{3}{*}{$\begin{array}{l}\text { Mutfakta } \\
\text { Toplam } \\
\text { Deneyim } \\
\text { Süresi }\end{array}$} & \multicolumn{8}{|c|}{ Tat alma öğrenilen bir duyudur. } \\
\hline & \multicolumn{2}{|c|}{ Evet } & \multicolumn{2}{|c|}{ Hayır } & \multicolumn{2}{|c|}{ Fikrim yok } & \multicolumn{2}{|c|}{ Toplam } \\
\hline & $\mathbf{n}$ & $\%$ & $\mathbf{n}$ & $\%$ & $\mathbf{n}$ & $\%$ & $\mathbf{n}$ & $\%$ \\
\hline 1-3 Yıl & 26 & 9,8 & 26 & 22,0 & 0 & 0,0 & 52 & 13,1 \\
\hline $4-6$ Yil & 46 & 17,3 & 22 & 18,6 & 4 & 33,3 & 72 & 18,2 \\
\hline $7-9$ Yll & 30 & 11,3 & 14 & 11,9 & 4 & 33,3 & 48 & 12,1 \\
\hline 10 Yll ve Üzeri & 164 & 61,7 & 56 & 47,5 & 4 & 33,3 & 224 & 56,6 \\
\hline Toplam & 266 & 100,0 & 118 & 100,0 & 12 & 100,0 & 396 & 100,0 \\
\hline Test Değeri & \multicolumn{8}{|c|}{$19.389 * *$} \\
\hline p & \multicolumn{8}{|c|}{$0.002 *$} \\
\hline
\end{tabular}

$* \mathrm{p}<0.05, * *$ Fisher's Exact Testi

Profesyonel mutfaklardaki toplam deneyim süresi ile tat alma öğrenilen bir duyudur arasındaki ilişkiyi test etmek için ki kare analizi uygulanmıştır. Bunun sonucunda, mutfaktaki toplam deneyim süresi ile tat alma öğrenilen bir duyudur arasında istatistiksel olarak anlamlı bir ilişki olduğu görülmektedir $\left(X^{2}=19.389, \mathrm{p}<0.05\right)$. Tat alma öğrenilen bir duyudur ifadesine evet cevabını veren katılımcıların \%61,7'sinin $(n=164)$, hayır cevabını veren katılımcıların \%47,5'inin ( $\mathrm{n}=56)$ mutfaktaki toplam deneyim süresinin 10 yıl ve üzeri olduğu görülmektedir. Katılımcıların mutfaklarda deneyim süresi arttıkça tat almanın öğrenilen bir duyu olduğu görülmektedir.

\subsection{Katılımcıların Lezzet ve Tat Hakkındaki Kelime Tanımlamaları ile İlgili Bulgular}

Katılımcılara son olarak açık uçlu sorumuzda lezzet ve tadın kelimelerle ifade edilmesi istenmiştir. 396 katılımcıların lezzet kavramında 9 ifade ortaya çıkarılmıştır. 396 katılımcının lezzet kelimelerinin bazıların kategorileştirilmiş, dolayısıyla lezzet için toplam 402 ifade görülmektedir (Tablo 7). Tat kavramında ise 7 ifade görülmektedir. Tat kavramı için ise 396 katılımcıdan 366 ifade ortaya çıkarılmıştır (Tablo 8). Bu ifadeler tat ve lezzetin tanımlanması ve farkının ortaya konulabilmesi açısından dikkat çekicidir.

Tablo 7. Kişilerin lezzeti tanımlayan ifadelerinin frekans dağılımı

\begin{tabular}{|l|c|c|}
\hline Lezzeti Tanımlayan İfadeler & $\mathbf{n}$ & $\mathbf{\%}$ \\
\hline $\begin{array}{l}\text { Nefis/Harika/Mükemmel/Çok } \\
\text { güzel }\end{array}$ & 204 & 50,7 \\
\hline Lezzetli/Lezzetsiz & 84 & 20,9 \\
\hline Tadı güzel & 30 & 7,5 \\
\hline Damak zevki & 30 & 7,5 \\
\hline Zevk/haz & 22 & 5,5 \\
\hline
\end{tabular}




\begin{tabular}{|l|c|c|}
\hline Aroması güzel & 10 & 2,4 \\
\hline Hoş koku & 8 & 2,0 \\
\hline İşah açıc1 & 8 & 2,0 \\
\hline Kıvam & 6 & 1,5 \\
\hline Toplam & $\mathbf{4 0 2}^{*}$ & $\mathbf{1 0 0}$ \\
\hline
\end{tabular}

*Katılımcılar birden fazla ifade belirtmiştir.

Bu çalışmada, kişilerden lezzeti tanımlayan kellimeler sorulmuştur. 396 katılımcıdan 9 ifade çıkarılmıştır. Lezzeti tanımlayan kelimelerin \%50,7 ’si (n=204) “nefis/harika/mükemmel/çok güzel” gibi lezzeti imgeleyerek ifadelendirilmiştir. İfadelerden \%20,9 (n=84) oranı ile "lezzetli/lezzetsiz" izlemektedir. En düşük ifade ise "kıvam” \%1,5 (n=6) ‘dır.

Tablo 8: Kişilerin tadı tanımlayan ifadelerinin frekans dağılımı

\begin{tabular}{|l|c|c|}
\hline Tadı Tanımlayan İfadeler & Frekans & \% \\
\hline $\begin{array}{l}\text { Nefis/Harika/Mükemmel/Çok } \\
\text { güzel }\end{array}$ & 116 & 31,2 \\
\hline Tatların ifade edilmesi & 112 & 30,7 \\
\hline Tadı güzel & 56 & 15,4 \\
\hline Damak zevki & 32 & 8,8 \\
\hline Lezzetli & 24 & 6,6 \\
\hline Zevk/haz & 20 & 5,5 \\
\hline Aroma & 6 & 1,8 \\
\hline Toplam & $\mathbf{3 6 6}$ & $\mathbf{1 0 0}$ \\
\hline
\end{tabular}

Katılımcıların tadı açıklayan kelimeler istendiğinde, \%31,2 $(\mathrm{n}=116)$ oranında nefis, harika, mükemmel, çok güzel ifadelerini, $\% 30,7(n=112)$ oranında tatların ifade edilmesi ve $\% 15,4$ oranında tadı güzel ifadelerinin kullanıldığ tadı aroma ile ilişkilendirmiştir.

\section{SONUÇ VE ÖNERILER}

Tat ve lezzet kavramlarına ilişkin literatürde pek çok tanım bulunmaktadır. Gıda sektöründe sıklıkla kullanılan bu kavramların doğru şekilde kullanılması oldukça önemlidir. Hem toplumda hem de profesyonel aşçılar arasında bu kavramların bilinmeden birbirlerinin yerine kullanıldıkları görülmektedir. Aynı zamanda konuyla ilgili yapılan literatür araştırmalarında da bazı araştırmacıların bu kavramları birbirlerinin yerlerine kullanarak yanlış ifade ettiklerini görmek mümkündür. Literatürde genel olarak tat duyusunun lezzeti oluşturan etmenlerden biri olduğundan bahsedilmektedir. Aynı zamanda lezzet algısı genel olarak sadece hissedilen tat değil koku, doku ve görsel uyarıları da kapsayan ve pek çok faktörden (mevsim, yaş, kültür, cinsiyet vb.) etkilenen bir bütün olarak değerlendirilmektedir. Ancak kaynaklarda tat 
ve lezzet kavramlarının tanımlarının net şekilde yapılmaması ve ayırıcı noktalarının belirtilmemesi de bu karmaşıklığa neden olabilmektedir.

Çalışmamız sonucuna göre profesyonel aşçıların anket sorularında çoğunlukla doğru cevaplar verirken açık ifadelerde kavramları net şekilde tanımlayamadıkları tespit edilmiştir. Katılımcılar lezzet ve tat arasındaki ayrımı bildiklerini ifade etmelerine rağmen lezzet ve tada ilişkin yanlış bilgilere de sahip oldukları görülmektedir. Bu durumda profesyonel aşçıların lezzet ve tat kavramı arasındaki ayrımı bildiklerini düşündükleri ancak kavramlar arası ayrımı yeterince yapamadıkları görülmektedir. Dolayısıyla hipotezlerimizde H1'i destekler nitelikte değildir.

Literatürde yapılan lezzet tanımları içerisinde tat alma ve koku alma duyularının da etkili olduğu belirtilmektedir. Ancak çalışmamızda katılımcıların lezzet kavramı için kullandıkları ifadeler içinde "tadı güzel" ve "hoş koku" ifadelerinin çok düşük oranda olduğu belirlenmiştir. $\mathrm{Bu}$ durum da profesyonel aşçıların lezzet kavramının tanımlamasında ve etkileyen faktörler konusunda bilgi eksiklerinin olduğunu göstermektedir.

Sıklıkla birbiri ile karıştırılan bu iki kavramın net şekilde ayrımının yapılabilmesi için kavramların açık tanımlarının yapılması gerekmektedir. Aynı zamanda gastronomi eğitimi sürecinde ve mesleki süreçte tat ve lezzet algısı farklılı̆̆ ile ilgili gerekli eğitimlerin verilmesi önerilmektedir. Çalışmamız bu durumda gelecekteki konuyla ilgili çalışmalar için öncü niteliğindedir ve literatürde katkı sağlayacağını düşünmekteyiz. Ayrıca gelecekte lezzet ve tat ayrımının bilinirliği konusunda farklı katılımcılar ile özellikle çalışma yapılması önerilmektedir.

\section{KAYNAKÇA}

Abdi, H. (2002). What can cognitive psychology and sensory evaluation learn from each other? Food Quality and preference, 13(7-8), 445-451.

Auvray, M., \& Spence, C. (2008). The multisensory perception of flavor. Consciousness and cognition, 17(3), 1016-1031.

Boyacı, D. (2019). Duyuların lezzet algısı ve satın alma niyetine etkisi. (Yüksek Lisans Tezi), Aydın Adnan Menderes Üniversitesi, Sosyal Bilimler Enstitüsü, Gasteonomi ve Mutfak Sanatları Anabilim Dalı, Aydın 
Delwiche, J. (2004). The impact of perceptual interactions on perceived flavor. Food Quality and preference, 15(2), 137-146. doi:10.1016/S0950-3293(03)00041-7

Elder, R. S., \& Krishna, A. (2010). The effects of advertising copy on sensory thoughts and perceived taste. Journal of consumer research, 36(5), 748-756.

Han, P., Seo, H. S., Klockow, M., Yan, X., Hähner, A., \& Hummel, T. (2021). Oral irritation in patients with chemosensory dysfunction. Flavour and Fragrance Journal.

Heath, T. P., Melichar, J. K., Nutt, D. J., \& Donaldson, L. F. (2006). Human taste thresholds are modulated by serotonin and noradrenaline. Journal of Neuroscience, 26(49), 12664-12671.

Ishii, R., Yamaguchi, S., \& O'Mahony, M. (1992). Measures of taste discriminability for sweet, salty and umami stimuli: Japanese versus Americans. Chemical senses, 17(4), 365-380.

ISO. (1992). 5492. Terms relating to sensory analysis. International Organization for Standardization. Vienna: Austrian Standards Institute.

ISO. (2008). 5492. Terms relating to sensory analysis. International Organization for Standardization. Vienna: Austrian Standards Institute.

Johnson, B. \& Christensen, L. (2008). Educational Research: Quantitative, Qualitative, And Mixed Approaches. New York: Sage.

Karakuş, S. Ş. (2013). Tat Algılamayı Etkileyen Faktörler (Factor Affecting Perception of Taste). Journal of Tourism and Gastronomy Studies, 26, 34.

Karaman, E. E., \& Çetinkaya, N. (2020). Gıda Tercihinde Duyuların Rolü: Tat Duyusunun Tat Testi İle Demografik Özelliklere Göre Farklılığının Tespiti. Atatürk Üniversitesi Sosyal Bilimler Enstitüsü Dergisi, 24(2), 883-898.

Klausmeier, H. J. (1992). Concept learning and concept teaching. Educational Psychologist, 27(3), 267-286. doi:10.1207/s15326985ep2703_1

Klosse, P. (2019). The essence of gastronomy: Understanding the flavor of foods and beverages: CRC Press.

Krishna, A. (2012). An integrative review of sensory marketing: Engaging the senses to affect perception, judgment and behavior. Journal of consumer psychology, 22(3), 332-351.

Kurtuldu, E., Miloğlu, Ö., Derindağ, G., \& Özdoğan, A. (2018). Tat Duyu Bozukluklarına Genel Bakış. Atatürk Üniversitesi Diş Hekimliği Fakültesi Dergisi, 28(2), 277-283.

Lawless, H. (1991). The sense of smell in food quality and sensory evaluation. Journal of Food Quality, 14(1), 33-60.

Lawless, H., Rozin, P., \& Shenker, J. (1985). Effects of oral capsaicin on gustatory, olfactory and irritant sensations and flavor identification in humans who regularly or rarely consume chili pepper. Chemical senses, 10(4), 579-589. 
Lindemann, B. (1996). Taste reception. Physiological reviews, 76(3), 719-766.

McNabb, D. E. (2015). Research Methods For Political Science: Quantitative And Qualitative Methods. London: Routledge.

Mason, R. L., \& Nottingham, S. M. (2008). Sensory evaluation manual. Sensory Evaluation Manual. The University of Queensland.

Nagata, H., Dalton, P., Doolittle, N., \& Breslin, P. A. (2005). Psychophysical isolation of the modality responsible for detecting multimodal stimuli: a chemosensory example. Journal of Experimental Psychology: Human Perception and Performance, 31(1), 101.

Nakhleh, M. B. (1992). Why some students don't learn chemistry: Chemical misconceptions. Journal of chemical education, 69(3), 191.

Piqueras-Fiszman, B., \& Spence, C. (2012). The influence of the color of the cup on consumers' perception of a hot beverage. Journal of Sensory Studies, 27(5), 324-331.

Prescott, J. (2015). Multisensory processes in flavour perception and their influence on food choice. Current Opinion in Food Science, 3, 47-52.

Rozin, P. (1982). " Taste-smell confusions" and the duality of the olfactory sense. Perception \& psychophysics, 397-401. doi:10.3758/BF03202667

Sato, K., Endo, S., \& Tomita, H. (2002). Sensitivity of three loci on the tongue and soft palate to four basic tastes in smokers and non-smokers. Acta Oto-Laryngologica, 122(4), 74-82.

Savarin, B. (2018). Lezzetin fizyolojisi ya da yüce mutfak üzerine düşünceler (İkinci baskı) (Çeviren: Bucak, H.). İstanbul: Oğlak Yayıncılık (Eserin orijinali 1825'de yayımlandı).

Schiffman, S. S. (2000). Taste quality and neural coding: implications from psychophysics and neurophysiology. Physiology \& behavior, 69(1-2), 147-159.

Sencer, M. (1989). Toplum Bilimlerinde Yöntem. İstanbul: Beta Basım Yayım Dağıtım.

Shepherd, G. M., \& Shepherd, G. (2011). Neurogastronomy: Columbia University Press.

Sonis, S., Faizo, R., \& Fang, L. (2004). Ağız Hastalıklarının Sırları. (Çeviren: Hakkı Tanyeri). İstanbul: Nobel Tip Kitabevleri.

Spence, C. (2012). Auditory contributions to flavour perception and feeding behaviour. Physiology \& behavior, 107(4), 505-515. doi:10.1016/j.physbeh.2012.04.022

Spence, C., Levitan, C. A., Shankar, M. U., \& Zampini, M. (2010). Does food color influence taste and flavor perception in humans? Chemosensory Perception, 3(1), 68-84.

Spence, C., Smith, B., \& Auvray, M. (2015). Confusing tastes and flavours. Perception and its modalities, 247-274.

Stein, M., Larrabee, T. G., \& Barman, C. R. (2008). A study of common beliefs and misconceptions in physical science. Journal of Elementary Science Education, 20(2), 1-11. 
Türk Dil Kurumu (2021). Tat Nedir? [URL: https://sozluk.gov.tr/] (Erişim tartihi: 20 Haziran 2021).

Tournier, C., Sulmont-Rossé, C., \& Guichard, E. (2007). Flavour perception: aroma, taste and texture interactions. In (pp. 246-257): Global Science Books.

Üce, M., \& Ceyhan, İ. (2019). Misconception in Chemistry Education and Practices to Eliminate Them: Literature Analysis. Journal of Education and Training Studies, 7(3), 202-208.

Viana, F. (2011). Chemosensory properties of the trigeminal system. ACS chemical neuroscience, $2(1), 38-50$.

1. Çıkar Çatışması Beyanı: Makale yazarları aralarında herhangi bir çıkar çatışması olmadığını beyan etmektedirler.

2. Etik Kurul İzin Belgesi: Araştırma yapılmadan önce Kapadokya Üniversitesi Bilimsel Araştırma ve Yayın Etiği kurulundan 08.03.2021 tarihinde "Etik Kurul” izni alınmıştır. (Karar no: 2021.51)

3. Araştırmacıların Katkı Oranı Beyanı: Yazarlar makaleye eşit oranda katkı sağlamış olduklarını beyan etmektedirler. 


\section{Determination of Knowledge Levels of Professional Chefs on Taste and Flavour Concepts}

\section{Dorukan BOYACI}

Kapadokya University, Cappadocia Vocational College, Nevşehir/Turkey

\section{Melih İÇİGEN}

Kapadokya University, Cappadocia Vocational College, Nevşehir/Turkey

\section{Extensive Summary}

The concepts of taste and flavor are two concepts that are used interchangeably. There are many different definitions of these concepts. While the concept of taste is defined as the five tastes (sweet, bitter, sour, salty and umami) in the tongue, the concept of taste is defined as the complex component of olfaction, taste and trigeminal sensations according to the International Standards Organization. However, people confuse taste and flavor in their daily lives. Therefore, it is important to determine the usage of these two concepts and their correct use, especially in professional fields. In this study, it is aimed to determine the knowledge levels of the two concepts in the food and tourism sector. The aim of this study is to reveal whether the professional chefs who are members of the Turkish Chef Federation (TAŞFED) know the concepts of taste and taste correctly when cooking or explaining their foods, and whether they use these words correctly in the professional business field.

Incorrect definition of a concept is given as a misconception in the literature. In the growing field of flavor perception research, answering the question of what exactly distinguishes taste from flavor has been said to be critical, as it has broader implications for discussions about how we should distinguish the difference. In this study, a general literature review was conducted. The definitions of the concepts of taste and flavor and the phenomena that affect the perception of taste are explained in detail. Therefore, the complex structure of flavor is shown. In other words, the discourse that a food tastes good by referring to its taste has been emphasized based on the literature.

The method of this study is quantitative research method. The universe of this study consists of 18,000 members affiliated with TAŞFED. The sample of the study was calculated as 377 with $95 \%$ confidence interval. In this study, data were collected by sending the questionnaire 
form to 396 participants online. In addition, two open-ended questions were asked to the participants in order to determine the meaning differences of the words taste and flavor.

The data obtained in the study were analyzed as a result of the chi-square test. According to the chi-square analysis results of the study, the difference between taste and flavor seems to be known as the professional title and experience of professional cooks increase. However, according to the open-ended answers of the participants, the words taste and taste resulted in two types. First, words describing taste and flavor are explained by imagination. In other words, participants often use words such as "Delicious, nice, wonderful". Second, apart from the images used, the participants describe taste and flavor with different words. For example, the expression "taste good", which is one of the expressions describing the taste, proves that according to the literature, the concepts of taste and taste are not fully known by the participants. Therefore, the H1 hypothesis of the study was not supported. This shows that professional chefs lack knowledge in defining the concept of taste. 